\title{
Processo de identificação: entre a memória e a história
}

\author{
Proceso de identificación: entre la memoria y la historia \\ Identification process: between memory and history
}

\author{
Naiara Souza da Silva ${ }^{1}$ \\ Stella Aparecida Leite Lima
}

\begin{abstract}
Resumo
Este trabalho reúne reflexões acerca da linguagem, da história, da ideologia e do inconsciente na construção da identidade do sujeito, esta resultante de processos de identificação. Fundamentadas na teoria interpretativa da Análise de Discurso (AD), de filiação em Michel Pêcheux, nosso interesse está em compreender a historicidade de sentidos atribuídos ao estado do Rio Grande do Sul, para analisar a tatuagem da bandeira Farroupilha materializada no corpo de determinado sujeito. Nesse caminho, recorremos à memória, enquanto categoria de análise, procurando compreender o funcionamento da discursividade presente na tatuagem em questão.
\end{abstract}

Palavras-chave: Identificação; Memória; Tatuagem.

\section{Resumen}

Este trabajo reúne reflexiones acerca del la lenguaje, de la historia, de la ideología y del inconsciente en la construcción de la identidad del sujeto, ésta resultante de procesos de identificación. En la teoría interpretativa del Análisis de Discurso (AD), de filiación en Michel Pêcheux, nuestro interés está en comprender la historicidad de los sentidos atribuidos al estado de Rio Grande do Sul, para analizar el tatuaje de la bandera Farroupilha materializada en el cuerpo de determinado sujeto. En ese camino, recurrimos a la memoria, como categoría de análisis, buscando comprender el funcionamiento discursivo presente en el tatuaje en cuestión.

Palabras claves: Identificación; Memoria; Tatuaje.

\section{Abstract}

This paper focuses its reflections on language, history, ideology and unconscious in the subject's identity construction, the result of the identification process. By the Discourse Analyses of Michel Pêcheux, our interest is to comprehend the sense historicity on the Rio Grande do Sul state by the analyze of a Farroupilha tattoo, materialized on a specific subject body. In this way, we utilize memory notion while an analyze category, with the aim to comprehend the discursiveness function present in the tattoo concerned.

Keywords: Identification; Memóry; Tattoo.

\section{Um início}

Este texto resulta de outras reflexões ${ }^{3}$ propostas acerca da linguagem, da história, da ideologia e do inconsciente na construção da identidade do sujeito, ainda que entendemos a

\footnotetext{
${ }^{1}$ Doutoranda em Letras; Curso de Pós-Graduação em Letras: Linguística Aplicada da Universidade Católica de Pelotas; Pelotas, Rio Grande do Sul, Brasil; naiaraa_souza@ hotmail.com. Trabalho apresentado no III Encontro Humanístico Multidisciplinar e II Congresso Latino-Americano de Estudos Humanísticos Multidisciplinares Interlocuções com o contexto político atual, realizado nos dias 7 a 9 de novembro de 2017 na Universidade Federal do Pampa (UNIPAMPA)/campus Jaguarão.

2 Mestre em Letras; Curso de Pós-Graduação em Letras: Linguística Aplicada da Universidade Católica de Pelotas; Pelotas, Rio Grande do Sul, Brasil; staple_li@hotmail.com.
} 
identidade enquanto processo de identificação, e não como algo estático. Nosso interesse está em compreender a historicidade de sentidos atribuídos ao estado do Rio Grande do Sul, Brasil, para analisarmos a tatuagem da bandeira Farroupilha materializada no corpo de determinado sujeito.

Explicamos que este trabalho se fundamenta na teoria interpretativa da Análise de Discurso (AD), cujo precursor teórico é o filósofo Michel Pêcheux (1990/2010) (1988/2009) 4 . Esta teoria nos dá respaldo para trabalharmos os processos discursivos constitutivos dos sentidos, não os concebendo numa perspectiva objetiva apenas. Quanto ao sujeito, entendemos que ao se deparar com o simbólico, o ser humano é instado à interpretar o mundo, sendo sua interpretação ligada diretamente a sua filiação ideológica. O sujeito, nessa perspectiva, não é nem dono nem fonte daquilo que diz; ao contrário, encontra-se submetido ao inconsciente e à ideologia, vivendo na ilusão de subjetividade.

Ao tatuar-se, entendemos que a tatuagem ao representar o sujeito, significa, produzindo sentidos. Assim, a tatuagem é compreendida como um texto, ou seja, uma materialidade discursiva na qual o sentido não é dado de antemão. Conforme a leitura de Silva (2014), já podemos observar essa proposição, quando a autora escreve que as tatuagens podem produzir diferentes sentidos materializados no corpo de sujeitos porque os sentidos não estão unicamente no desenho/imagem que a tatuagem representa, mas se constituem em consonância ao imaginário, ao inconsciente, às condições de produção e à memória que o sujeito mobiliza quando se tatua.

Dadas as primeiras considerações, apresentamos nossa problemática: como a tatuagem da bandeira Farroupilha contribui para o resgate de sentidos advindos de outra época histórica? Desse modo, procurando compreender o funcionamento da discursividade presente nesta tatuagem, buscamos amparo na noção de memória discursiva, enquanto categoria de análise. Reforçamos que não buscamos um sentido verdadeiro que estaria oculto na tatuagem da bandeira Farroupilha, nosso objeto de análise, mas buscamos desconstruir os processos discursivos que levam às evidências, bem como o que esses mesmos processos deixam de fora (cf. MITTMANN, 2007).

Para tanto, tratando-se da metodologia que utilizamos, nosso gesto de leitura ancora-se na $\mathrm{AD}$, através da qual podemos compreender como o corpo do sujeito tatuado funciona como

\footnotetext{
${ }^{3}$ A primeira, em torno do tema deste trabalho, foi publicada como resumo expandido no XVII Encontro de PósGraduação (ENPOS) da Universidade Federal de Pelotas (UFPEL), em 2015. Outra versão abordando aspectos diferentes foi publicada na Revista Rua, em 2017.

${ }^{4}$ A formatação desta bibliografia está disposta na seguinte ordem: o primeiro ano refere-se a 1. edição da obra/a segunda data refere-se a edição que estamos utilizando no presente estudo.
} 
um lugar de memória, na medida em que é nele que se materializam discursos. Observamos, também, as implicações que decorrem da consolidação de um imaginário farroupilha que, pelo regime de repetição de sentidos advindos de uma região de saber, alimenta o que é memorável para um grupo social, sejam os habitantes do estado do RS.

\section{Nosso gesto de leitura}

A fotografia da tatuagem da bandeira foi publicada na rede social denominada Facebook $^{5}$, no dia 22 de setembro de 2012, pelo tatuador em seu perfil pessoal, marcando o local em que trabalha e o nome do sujeito tatuado, utilizando a legenda de sua postagem “Semana Farroupilha. Ótimo find!”. Ou seja, na semana em que se comemoram os ideais farroupilhas, determinado sujeito tatuou em seu corpo discursos relacionados ao seu sentimento pelo Estado, (re)produzindo sentidos. Estes sentidos podem ser relacionados a tantos outros discursos que circulam socialmente próprios ao tradicionalismo, como aqueles presentes na literatura, em músicas, programas de rádio e televisivos. Dentre todos, podemos citar a composição de Elton Saldanha, "Eu sou do sul, é só olhar para ver que eu sou do sul".

Vejamos:

Figura 1 - Fotografia da tatuagem da bandeira Farroupilha do sujeito tatuado

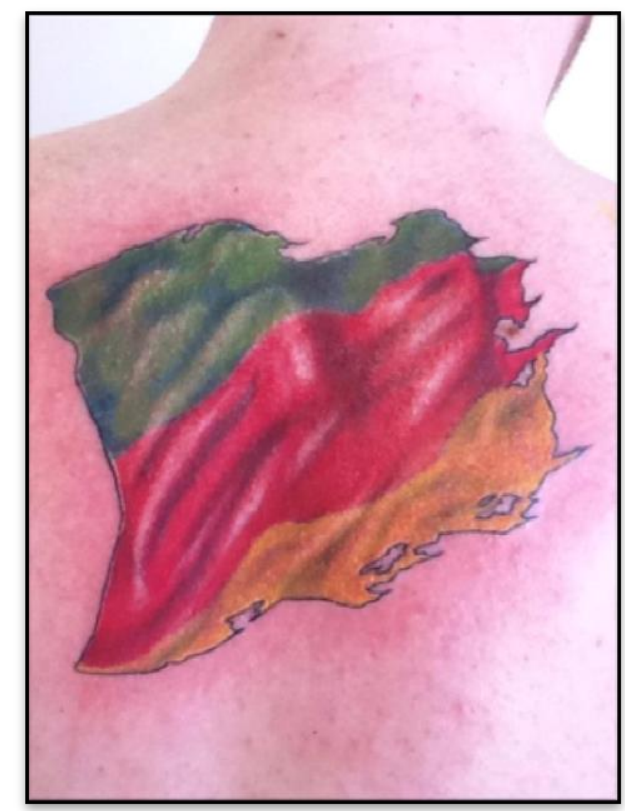

Fonte: Disponível em: Arquivo das autoras. Foto tirada em: 04/06/2015

O corpo, no viés que trabalhamos, é concebido como um dispositivo de visualização, como modo de ver o sujeito, suas condições de produção, sua historicidade e a cultura que o

\footnotetext{
${ }^{5}$ Site: www.facebook.com.br.
} 
constitui (cf. LEANDRO-FERREIRA, 2013). Compreendemos que o sujeito se identifica com o seu corpo para significar e, na sua textualização, por meio da tatuagem, o sujeito registra na pele o seu desejo, a sua interpretação e a sua interpelação. Para Castro (2005), o sujeito toma para si a responsabilidade de desenhar seu próprio corpo, como forma de definir sua identidade e estilo de vida. Na contemporaneidade, não há como negar o discurso da corpolatria existente e, nesse contexto, os sujeitos expõem o seu corpo, como objeto de contemplação e de sedução, no nosso caso, retomamos Saldanha "é só olhar para ver que eu sou do sul".

Levando em consideração tais entendimentos, no texto que trazemos como objeto devido nossa inquietação, um dos pontos que levantamos à análise diz respeito ao estranhamento que tivemos ao observar a diferença entre a bandeira tatuada pelo sujeito, no período da Semana Farroupilha, e a bandeira atual do Estado do Rio Grande do Sul, e isto só pode ser percebido se mobilizada a memória.

A noção de memória por nós utilizada respalda-se nos trabalhos de Indursky (2011) e (2015), somada ao entendimento de Nora (1993). Para a primeira autora citada, memória discursiva se distingue de toda memorização psicológica, e resulta de uma tomada de posição do sujeito, já que uma posição não aciona o todo dos saberes existentes, mas aquilo que ela consegue recuperar em termos de memória discursiva. Para o segundo autor, memória e história não são sinônimos; a memória é a vida e está em permanente evolução, aberta à dialética da lembrança e do esquecimento, já a história é a reconstrução problemática e incompleta do que não existe mais. Nas próprias palavras de Nora (1993), "a memória é um fenômeno sempre atual, um elo vivido no eterno presente; a história, uma representação do passado" (p. 09).

Assim, se bem entendemos os dois autores, importa-nos observar não a linearidade da história, mas o modo como ela se inscreve nos processos discursivos. Dito isso, interessa-nos trabalhar com a noção de historicidade e não, com a noção de história do ponto de vista cronológico, porque é a historicidade que reafirma a relação constitutiva entre linguagem e exterioridade.

Nesse caminho, retomando nosso objeto de análise, a nosso ver, surge um elemento da ordem do inesperado, conforme trabalha Ernst-Pereira (2009), pois a tatuagem da bandeira Farroupilha foi materializada no corpo de determinado sujeito no contexto sócio-histórico da contemporaneidade. Sendo assim, o esperado seria encontrarmos outro desenho, na medida em que as condições de produção em que o sujeito tatuado está inscrito referem-se à contemporaneidade. Dito de outra forma, mesmo reconhecendo que as cores utilizadas pelo 
referido sujeito remetam às cores que representam o Estado, a imagem não condiz com a da época em que esta tattoo foi materializada.

Isto nos leva a pensar que a tatuagem, enquanto formulação/texto, faz circular formulações anteriores, discursos outros, e com isso, produz efeitos de memória específicos, já que o desenho materializado no corpo do sujeito é uma réplica da primeira bandeira da República Rio-Grandense, não é a bandeira oficial do Estado do século XXI. Considerando que sentidos podem ser sempre outros, o que não significa que eles possam ser qualquer um, nem que todas as interpretações sejam equivalentes, nos questionamos como a memória discursiva atua na produção de sentidos na leitura da tatuagem? Pensamos nessa questão porque nos interessa saber como o trabalho da memória permite a lembrança, a repetição, a refutação e até o esquecimento de saberes quando formulados pelo sujeito tatuado em seu discurso.

A imagem utilizada pelo sujeito trata-se de uma bandeira dividida em três cores que, imaginariamente, simbolizam o verde e o amarelo da bandeira da época do Império, com o vermelho ao centro, que representa a cor do sangue daqueles que lutavam em busca da liberdade da província. Conforme contam alguns historiadores, essa bandeira foi utilizada em inúmeras batalhas pelos gaúchos, tanto em combates durante a revolução quanto após o seu término, como na guerra do Paraguai. Entendemos que se instaura aqui uma memória local, reforçada por aparelhos de estado (cf. ALTHUSSER, 1970), que pode ser (re)produzida pelo regime de repetibilidade de sentidos.

Petri (2004) e (2009) trabalha sobre o imaginário construído e instituído sobre o gaúcho. De acordo com a autora, temos, na memória coletiva, representações imaginárias do gaúcho, não como bandido ou malfeitor, mas como um exímio soldado, e é a partir do trabalho da memória e do discurso que é produzido em torno desse imaginário do gaúcho, que somos conduzidos a lembrar e/ou a esquecer, a produzir sentidos.

Acionando e retomando a categoria de análise da memória discursiva, podemos recuperar, dessa forma, por um gesto de resgate da memória (cf. INDURSKY, 2015), efeitos de sentido separatistas e ufanistas que podem emergir de uma rede de saberes e que, a nosso ver, se materializam na tatuagem do sujeito em questão, aqui considerada como portadora de discursividade. Assim, acreditamos tratar-se de um corpo que serve como meio para que o sujeito se inscreva socialmente, trazendo desenhado em sua pele a tatuagem da bandeira Farroupilha rasgada. Entendemos que tal característica também significa acentuando os sentidos separatistas e ufanistas, produzindo efeitos mais do que estéticos. Em nosso ponto de vista, podemos parafrasear esses efeitos de sentido produzidos pela característica rasgada com 
sentidos da canção "não tá morto quem peleia" de Iedo e Fernandes, que resgatam sentidos do imaginário do gaúcho heroico postulado nos trabalhos de Petri (2004) e (2009).

Nessa ótica, o corpo pode desempenhar um lugar de memória, seguindo a orientação de Indursky (2011), porque consolida o imaginário do gaúcho "forte, aguerrido e bravo", e torna possível a repetição de discursos que alimentam o que é memorável para um grupo social. A partir de sentidos positivos reforçados e cristalizados, o sujeito, uma vez identificado com os mesmos, textualiza em seu corpo a imagem da bandeira dos Farrapos, ressaltando seu amor pelo Estado, sua aproximação aos pressupostos separatistas, e dá visibilidade ao seu orgulho por/de ser gaúcho. Nessa direção, podemos pensar que se silenciam, portanto, sentidos negativos - aqueles relacionados ao gaúcho rebelde, recalcando-os num espaço que Indursky (2015) denomina de dobradura de memória. Para a autora, quando se jogam memórias na dobradura, constrói-se o que chama de desmemória, uma prática de apagamento, de esquecimento de fatos.

\section{Um efeito de fechamento}

Como vimos ao longo do texto, a produção de sentidos à tatuagem da bandeira Farroupilha, tanto pode se dar em função da repetibilidade, do silenciamento, quanto pela instauração de sentidos outros. Pelo jogo de repetição discursiva, o sujeito traz no fio de seu discurso, precisamente na textualização da tatuagem, um pré-construído, um elemento de discurso que foi produzido anteriormente, em outro discurso.

O sujeito tatuado ao textualizar seu corpo a tatuagem da bandeira, a realiza sob o regime de repetibilidade, afetado pelo esquecimento. Indursky (2011) nos lembra que, "se há repetição é porque há retomada/regularização de sentidos que vão construir uma memória social, mesmo que esta se apresente ao sujeito do discurso revestida da ordem do não-sabido" (p. 71).

Nora (1993) salienta que produzir arquivo seria o imperativo da época. Assim, "nos sentimos obrigados a acumular religiosamente vestígios, testemunhos, documentos, imagens, discursos, sinais visíveis do que foi" (p. 15), ou seja, os sujeitos buscam suportes para materializar memórias, para que estas não desapareçam. Trazendo sua formulação: "arquivese, arquive-se, sempre sobrará alguma coisa!” (NORA, 1993, p. 16).

No caso que trazemos, para finalizarmos, o corpo torna-se lugar de memória, e isto ocorre, relacionando ao trabalho de Nora (1993), porque não há mais memória espontânea. Sendo assim, é preciso criar arquivos, manter aniversários e organizar celebrações, e nós 
acrescentamos, ao concordar com ele, que é preciso também, fazer uma tatuagem. Na falta de memória, os lugares de memória serão lugares de história.

\section{Referências}

ALTHUSSER, Louis. Ideologia e Aparelhos Ideológicos do Estado. Tradução de Joaquim José de Moura Ramos. Lisboa: Presença, 1970.

CASTRO. Ana Lúcia de. Culto ao corpo: identidades e estilos de vida. In: Corpo território da cultura. Organizadoras: Maria Lúcia Bueno e Ana Lúcia de Castro. São Paulo: Annablume, 2005.

ERNST-PEREIRA, Aracy. A falta, o excesso e o estranhamento na constituição/interpretação do corpus discursivo. IV SEMINÁRIO DE ESTUDOS EM ANÁLISE DO DISCURSO: 19692009: MEMÓRIA E HISTÓRIA NA/DA ANÁLISE DO DISCURSO - IV SEAD, 10 a 13 de nov., 2009. Porto Alegre. Anais do evento, 2009.

INDURSKY, Freda. A memória na ceda do discurso. In: Memória e história na/da Análise de Discurso. Organizadoras: Freda Indursky, Solange Mittmann e Maria Cristina Leandro Ferreira. Campinas, SP: Mercado das Letras, 2011.

Políticas do esquecimento x Políticas de resgate da memória. In: Análise de Discurso em Rede: Cultura e Mídia. Organizadoras: Giovanna Benedetto, Nádia Neckel e Solange Gallo. Campinas, SP: Pontes Editores, 2015.

LEANDRO-FERREIRA, Maria Cristina. O Corpo enquanto objeto discursivo. In: Análise do Discurso em perspectiva: teoria, método e análise. Organizadoras: Verli Petri e Cristiane Dias. Santa Maria: Editora da UFSM, 2013.

MITTMANN, Solange. Análise do discurso no Brasil: mapeando conceitos, confrontando limites. Organizadoras: Maria Cristina Leandro Ferreira e Freda Indursky. São Carlos: Claraluz, 2007.

NORA, Pierre. Entre memória e história: a problemática dos lugares. Projeto História. Tradução: Iara Aun Khoury. São Paulo, n. 10. Dez., 1993.

PÊCHEUX, Michel. Por uma análise automática do discurso. 4. ed. Tradução: Bethania Mariani et al. Oganizadores: Françoise Gadet e Tony Hak. Campinas, SP: Editora da Unicamp, 1990/2010.

Semântica e Discurso: uma crítica a afirmação do óbvio. Tradução: Eni Puccinelli Orlandi et al. 4. ed. Campinas, SP: Editora da Unicamp, 1988/ 2009.

PETRI, Verli. Imaginário sobre o gaúcho no discurso literário: da representação do mito em 'Contos Gauchescos', de João Simões Lopes Neto, à desmitificação em 'Porteira Fechada', De Cyro Martins. 2004. 332 f. Tese de Doutorado. Universidade Federal do Rio Grande do Sul - UFRGS. Porto Alegre, mai., 2004. 
A produção de sentidos sobre o gaúcho: um desafio social no discurso da história e da literatura. Conexão Letras. Revista do Programa de Pós-Graduação em Letras da UFRGS, Porto Alegre, n. 4, 2009.

SILVA, Naiara. Tatuagens: sujeitos e sentidos. 2014. 153f. Dissertação de mestrado. Universidade Católica de Pelotas - UCPEL. Pelotas, dez., 2014. 